\title{
A CADAVERIC STUDY OF THE MYOCARDIAL BRIDGES
}

\author{
Suganya Saminathan ${ }^{1}$, Vishnuvarthan Selvaraj ${ }^{2}$
}

1Assistant Professor, Department of Anatomy, Karpagam Faculty of Medical Sciences and Research, Coimbatore, Tamilnadu, India. ${ }^{2}$ Associate Professor, Department of General Surgery, Karpagam Faculty of Medical Sciences and Research, Coimbatore, Tamilnadu, India.

\begin{abstract}
BACKGROUND
Myocardial bridging is a congenital anomaly, where a segment of an epicardial coronary artery is undercover of myocardial fib res for a variable distance and the underlying arterial segment is described as a mural coronary artery or a tunnelled artery. The history of myocardial bridges dates back to 1737 when it was first recognized by Reyman and then by Black in 1805 . The first detailed post mortem examination of myocardial bridges was done by Geiringer in 1951 and the first radiological description was given by Portmann and Iwig in 1960. The bridged segment of the coronary artery is susceptible to various pathophysiological mechanisms leading to myocardial ischemia, especially when associated with other cardiovascular diseases. The myocardial bridges were initially thought to be innocent bystanders in the development of acute coronary syndromes. But in the last two decades, the outlook has changed with the increasing incidence of sudden cardiac deaths in young athletes, where myocardial bridges were the only finding at autopsy. The mechanism by which the myocardial bridges induce clinical symptoms is uncertain, but among the proposed are vasospasm, thrombus formation, endothelial dysfunction and impaired coronary flow reserve. Most important of these is the dynamic systolic compression of the tunnelled artery with sustained early diastolic diameter reduction.

The aim of this study is to provide more information on the incidence of myocardial bridges, arterial preponderance for myocardial bridging, the length of the bridged segment and multiple bridging.
\end{abstract}

ABSTRACT

\section{MATERIALS AND METHODS}

A descriptive study of fifty formalin fixed hearts from the department of anatomy were dissected by conventional dissection methods as guided by Cunningham.

\section{RESULTS}

Myocardial bridges were found in 18 (36\%) hearts with a total of about 28 bridges. Most common artery involved was the anterior inter ventricular artery (66.6\%), which even had multiple bridges over it. The mean length of the bridges was $26.54 \mathrm{~mm}$.

\section{CONCLUSION}

From the present study, we infer that the presence of myocardial bridges in an unsuspected population is relatively higher. The definitive role of these bridges in acute coronary syndromes is yet uncertain. But owing to its higher rate of detection in those with myocardial ischemia, it is better to screen for the bridges along with other aetiological factors and treat the patients prophylactically. Of the imaging modalities, CT Coronary Angiography is found to be the investigation of choice. In the near future, holistic studies involving cadaveric, radiologic and clinical data are mandatory in researching the myocardial bridges.

\section{KEY WORDS}

Myocardial Bridges, Myocardial Ischemia, Atherosclerosis, Tunnelled Artery, Systolic Compression.

HOW TO CITE THIS ARTICLE: Saminathan S, Selvaraj V. A cadaveric study of the myocardial bridges. J. Evolution Med. Dent. Sci. 2019;8(02):133-136, DOI: 10.14260/jemds/2019/29

\section{BACKGROUND}

Myocardial bridging is a congenital anomaly, in which an epicardial coronary artery lies in the myocardium for part of its course. The bridged segment of the coronary artery is susceptible to various pathophysiological mechanisms leading to myocardial ischemia, especially when associated with other cardio vascular diseases. Recently, myocardial bridges have become a main topic of interest owing to its probable causation of sudden cardiac death in young athletes.

'Financial or Other Competing Interest': None.

Submission 07-12-2018, Peer Review 01-01-2019,

Acceptance 08-01-2019, Published 14-01-2019.

Corresponding Author:

Dr. Suganya Saminathan,

Assistant Professor,

Department of Anatomy,

Karpagam Faculty of Medical Sciences and Research,

Coimbatore, Tamilnadu, India.

E-mail: suganss02@gmail.com

DOI: $10.14260 /$ jemds $/ 2019 / 29$ the arteries with myocardial bridges. Of the fifty formalin fixed hearts dissected, myocardial bridges were found in 18 (36\%) hearts with a total of about 28 bridges. Most common artery involved was the anterior inter ventricular artery, which even had multiple bridges over a single artery. The mean length of the bridges was $26.54 \mathrm{~mm}$.

Myocardial bridging is a congenital anomaly, where a segment of an epicardial coronary artery is undercover of myocardial fibres for a variable distance and the underlying arterial segment is described as a mural coronary artery or a tunnelled artery. ${ }^{1}$ (Fig. 1). 


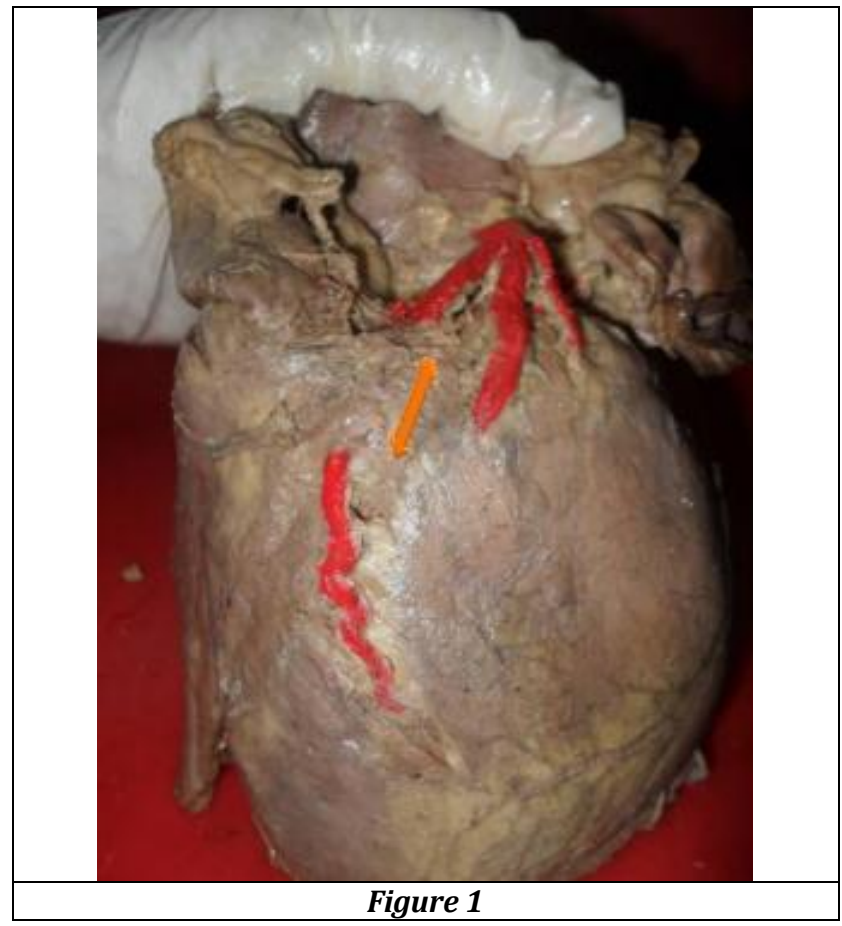

The history of myocardial bridges dates back to 1737 when it was first recognized by Reyman ${ }^{2}$ and then by Black ${ }^{3}$ in 1805. The first detailed post mortem examination of myocardial bridges was done by Geiringer 4 in 1951 and the first radiological description was given by Portmann and Iwig5 in 1960.

The myocardial bridges were initially thought to be innocent bystanders in the development of acute coronary syndromes. But in the last two decades, the outlook gets changed with the increasing incidence of sudden cardiac deaths in young athletes, where myocardial bridges were the only finding at autopsy. ${ }^{6}$

The mechanism by which the myocardial bridges induce clinical symptoms is uncertain, but among the proposed are vasospasm, thrombus formation, endothelial dysfunction and impaired coronary flow reserve. Most important of these is the dynamic systolic compression of the tunnelled artery with sustained early diastolic diameter reduction. ${ }^{7}$

\section{Embryological Consideration}

Embryologically, there are two theories for the development of myocardial bridges.

1. The myocardial bridges are primary structures, which are isolated from the rest of the myocardium by the sudden, intra myocardial course taken by the coronary artery.

2. The myocardial bridges are secondary structures, which are formed by the migration of the myocytes over the sub-epicardial coronary artery.

\section{Comparative Anatomy}

The coronary arteries are classified into three types with respect to the presence or absence of the myocardial bridges.

Type I: Coronary arteries are intra myocardial as seen in rodents, goats and sheep.

Type II: Coronary arteries are predominantly sub epicardial; myocardial bridges are occasionally present as in humans, gorilla and carnivores.
Type III: Coronary arteries are always sub epicardial as seen in horses and pigs.

\section{MATERIALS \& METHODS}

A Descriptive study of 50 formalin fixed hearts were studied by conventional dissection method.

\section{RESULTS}

\section{Number of Bridges}

Of the 50 hearts studied, 18 (36\%) hearts had about 28 myocardial bridges. Of these, 9 (18\%) hearts had single bridge, $8(16 \%)$ hearts had double bridges and one $(2 \%)$ heart had triple bridges. (Table. 1)

\begin{tabular}{|c|c|}
\hline No. of Myocardial Bridges & No. of Hearts \\
\hline Single & $9(18 \%)$ \\
\hline Double & $8(16 \%)$ \\
\hline Triple & $1(2 \%)$ \\
\hline \multicolumn{2}{|c|}{ Table 1 } \\
\hline
\end{tabular}

\section{Vessels Involved}

Of the vessels involved, the most common was over the anterior inter ventricular artery (66.6\%) (Fig. 2), followed by left marginal artery (27.7\%), left diagonal artery (16.7\%), right coronary artery (11.2\%) and left circumflex artery $(5.5 \%)$ in decreasing order. (Table. 2 )

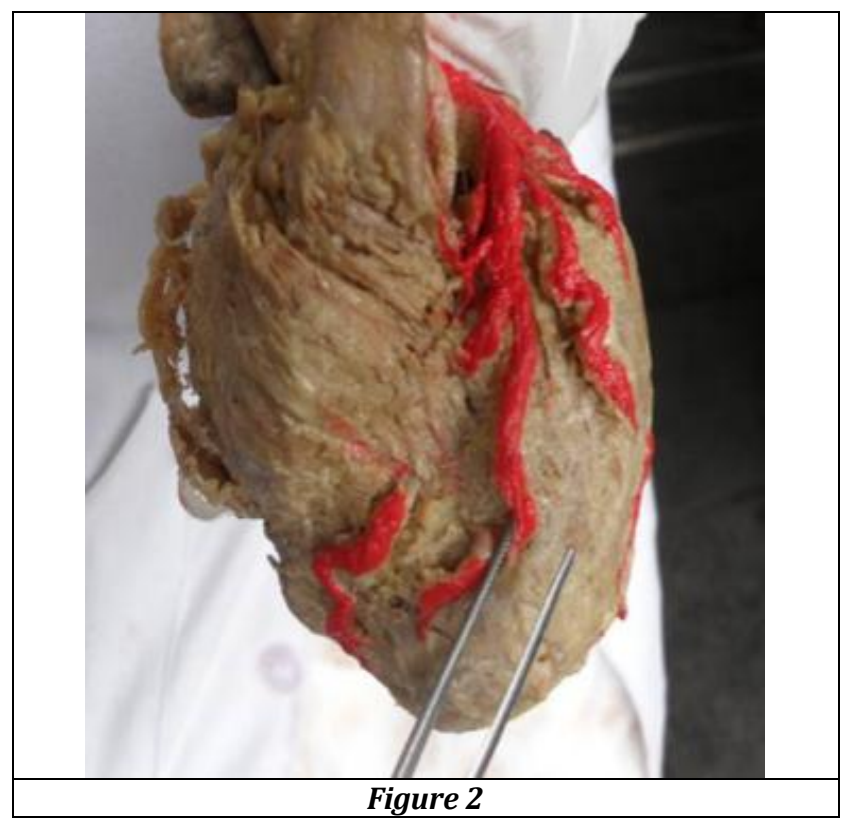

\begin{tabular}{|c|c|}
\hline Vessel Involved & No. of Hearts \\
\hline $\begin{array}{c}\text { Anterior Inter Ventricular } \\
\text { Artery }\end{array}$ & $12(66.6 \%)$ \\
\hline Left Marginal Artery & $5(27.7 \%)$ \\
\hline Left Diagonal Artery & $3(16.7 \%)$ \\
\hline Right Coronary Artery & $2(11.2 \%)$ \\
\hline Left Circumflex Artery & $1(5.5 \%)$ \\
\hline \multicolumn{2}{|c|}{ Table 2 } \\
\hline
\end{tabular}

\section{Double Bridges}

Double bridges were present in $8(16 \%)$ hearts. Of these 8 hearts, multiple bridges over a single artery were found in 3 $(17 \%)$ hearts, involving only the anterior inter ventricular artery (Fig. 3). 


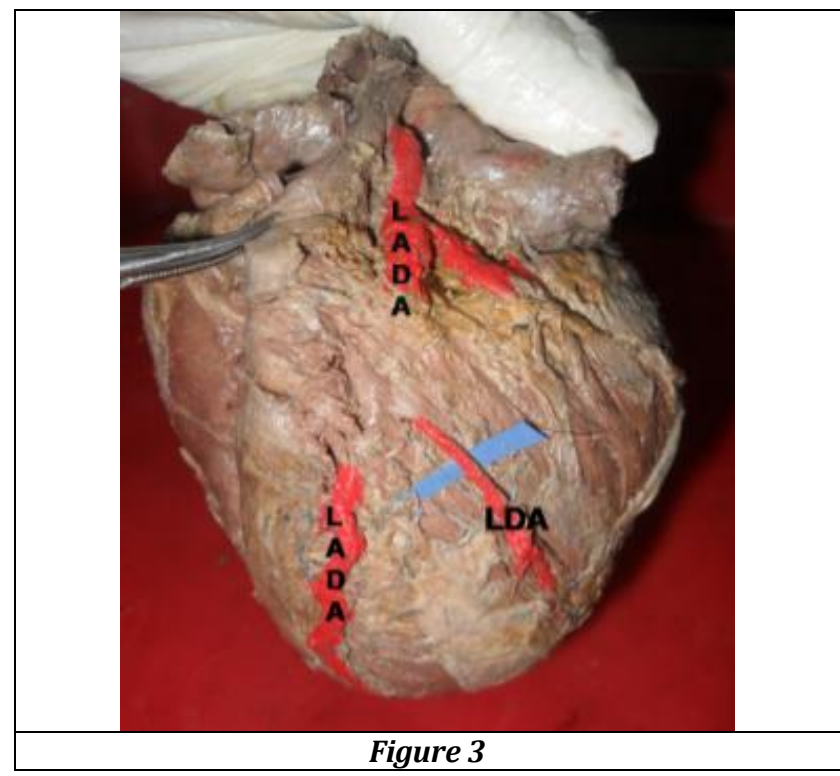

Of these 8 hearts, 5 (28\%) hearts had multi arterial bridging, involving the anterior inter ventricular artery (AIVA) and the left marginal artery (LMA) in $3(17 \%)$ hearts; involving the anterior inter ventricular artery and the left diagonal artery (LDA) in 2 (11\%) hearts (Fig. 4), (Table 3).

\begin{tabular}{|cc|c|}
\hline Multi Arterial Bridging & $\mathbf{5 ( 2 8 \% )}$ \\
\hline 1. & AIVA \& LMA & $3(17 \%)$ \\
\hline 2. & AIVA \& LDA & $2(11 \%)$ \\
\hline \multicolumn{2}{|c|}{ Table 3 } \\
\hline
\end{tabular}

\section{Triple Bridges}

Only $(2 \%)$ one heart had three myocardial bridges, all over the anterior inter ventricular artery (Fig. 5)

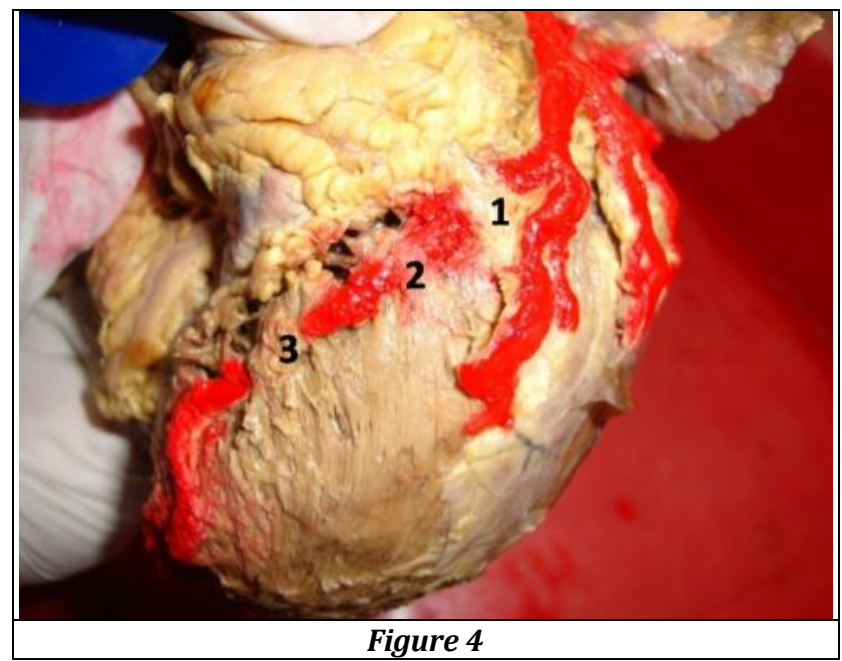

\section{Length of the Myocardial Bridges}

The length of the bridges ranged between 3 and $44 \mathrm{~mm}$ with a mean of about $26.54 \mathrm{~mm}$. (Fig. 6 and Fig. 7)

\section{DISCUSSION}

\section{Incidence of Myocardial Bridges}

- Edwards $^{8}$ (1956) observed myocardial bridges in $0.5 \%$ hearts.
- Polacek $^{9}$ (1961) reported the presence of myocardial bridges in $86 \%$ hearts.

- Ferreira $^{10}$ (1991) reported bridges in 56\% hearts.

- Baptista ${ }^{11}$ (1992) observed myocardial bridges in $54 \%$ hearts.

- $\quad$ Pelech $^{12}$ (2006) reported bridges in $25 \%$ hearts.

In the present study, myocardial bridges were observed in $36 \%$ hearts which is midway between the above values. (Table 4)

\begin{tabular}{|c|c|}
\hline Polacek & $86 \%$ \\
\hline Ferreira & $56 \%$ \\
\hline Baptista & $54 \%$ \\
\hline Pelech & $25 \%$ \\
\hline Edwards & $05 \%$ \\
\hline Present study & $36 \%$ \\
\hline \multicolumn{2}{|c|}{ Table 4 } \\
\hline
\end{tabular}

\section{Anterior Inter Ventricular Artery (AIVA) Involvement}

- Edwards ${ }^{8}$ (1956) quoted the involvement of AIVA in $87 \%$ hearts.

- Polacek $^{9}$ (1961) observed bridges over AIVA in $60 \%$ hearts.

- Baptista ${ }^{11}$ (1992) found the affection of AIVA by the bridges in $35 \%$ hearts.

In the present study, myocardial bridges were observed over the anterior inter ventricular artery in $67 \%$ of the hearts which is close to that of Polacek's study (Table 5)

\begin{tabular}{|c|c|}
\hline Edwards & $87 \%$ \\
\hline Polacek & $60 \%$ \\
\hline Baptista & $35 \%$ \\
\hline Present study & $67 \%$ \\
\hline \multicolumn{2}{|c|}{ Table 5 } \\
\hline
\end{tabular}

\section{CONCLUSION}

From the present study, we infer that the presence of myocardial bridges in an unsuspected population is relatively higher. The definitive role of these bridges in acute coronary syndromes is yet uncertain. But owing to its higher rate of detection in those with myocardial ischemia, it is better to screen for the bridges along with other aetiological factors and treat the patients prophylactically. Of the imaging modalities, CT Coronary Angiography is found to be the investigation of choice. In the near future, holistic studies involving cadaveric, radiologic and clinical data are mandatory in researching the myocardial bridges.

\section{REFERENCES}

[1] Angelini P, Trivellato M, Donis J, et al. Myocardial bridges: a review. Prog Cardiovasc Dis 1983;26(1):7588.

[2] Reyman HC. Dissertation de vasis cordis propriis. Haller Bibl Anat 1737;2:366.

[3] Black S. A case of angina pectoris with dissection. Memoirs Med Soc Lond 1805;6:41.

[4] Geiringer E. The mural coronary. Am Heart J 1951;41(3):359-68. 


\section{Jemds.com}

[5] Porstmann W, Iwig J. Intramural coronary vessels in the angiogram. Fortschr Geb Rontgenstr Nuklearmed 1960;92:129-33.

[6] Cutler D, Wallace JM. Myocardial bridging in a young patient with sudden death. Clin Cardiol 1997;20(6):581-3.

[7] Bourassa MG, Butnaru A, Lesperance J, et al. Symptomatic myocardial bridges: overview of ischemic mechanisms and current diagnostic and treatment strategies. J Am Coll Cardiol 2003;41(3):351-9.

[8] Edwards JC, Burnsides C, Lansing AI, et al. Arteriosclerosis in the intramural and extramural portions of coronary arteries in the human heart. Circulation 1956;13(2):235-41.

\section{Original Research Article}

[9] Polacek P, Kralove H. Relation of myocardial bridges and loops on the coronary arteries to coronary occlusion. Am Heart J 1961;61(1):44-52.

[10] Ferreira AG Jr, Trotter SE, Konig B Jr, et al. Myocardial bridges: morphological and functional aspects. $\mathrm{Br}$ Heart J 1991;66(5):364-7.

[11] Baptista CA, DiDio LJ. The relationship between the directions of myocardial bridges and of the branches of the coronary arteries in the human heart. Surg Radiol Anat 1992;14(2):137-40.

[12] Pelech AN. Coronary artery anomalies. 2006. www.emedicine.com. 